\title{
Stability Enhancement in Nine Bus System with STATCOM
}

\author{
Pushp Rai Mishra ${ }^{1}$, S. B. Warathe ${ }^{2}$ \\ ${ }^{1}$ (Department of Electrical \& Electronics Engineering, Dr.C.V.R.University Kargi Road Kota Bilaspur \\ Chattishgarh, India) \\ ${ }^{2}$ (Department of Electrical Engineering, Govt. Polytechnic Durg Chattishgarh, India)
}

\begin{abstract}
This work concentrates on improving the system stability and increase the stability margin by well know FACT device STATCOM in nine bus system. The STATCOM generally used for power quality improvement as well as enhancement of stability. The enhancement of stability shows the capability of STATCOM during disturbance.
\end{abstract}

Keywords: Nine Bus system, Power Swing, Load Angle, STATCOM, PASCAD.

\section{INTRODUCTION}

Static synchronous compensator (STATCOM) is a custom power device which is based on a voltage source converter (VSC) shunt connected to the network [1]. By injecting a controllable current, a STATCOM can mitigate voltage dip at the point of connected with the network and enhance system stability. This work will be focuses on the STATCOM for enhancement of power and damp out power swing. Firstly the characteristics of the STATCOM will studied, such as the required shunt compensation current, injected active and reactive power for given voltage dip magnitude. The pulse width modulation (PWM) strategy will be implementing in model. In order to obtain the phase and frequency information of grid voltage, phase-locked loop will be used in the controller system. The simulation model will design for power enhancement and transient stability in 9 bus system. All result will be simulated in PSCAD/EMTDC. The stability limit, also called the critical point, is often defined as the point where the power flow Jacobian is singular. As a consequence, attempts at power flow solutions near the critical point are prone to divergence and error. For this reason, double precision computation and anti divergence algorithms have been used in attempts to overcome the numerical instability [1-2]. The interest in system stability is due to the problems they cause on several effect on system. Adjustable-speed drives, process-control equipment, and computers are especially notorious for their sensitivity [3]. The typical enhancement of power by SVC and STATCOM is shown in figure-1.

\section{NINE BUS SYSTEM}

A Nine-bus three-machine system is described in Power System Control and Stability by Anderson and Fouad [4]. This system consist three generator and three large equivalent loads which are connected in a meshed transmission network through transmission lines as shown in figure2. In This system the generators are dynamically modelled with the classical equivalent model. A case study will be presented here on a small nine-bus power system [4] that has three generators and three loads a single-line impedance diagram for the system with STATCOM is shown in figure-2. Generator data for the three machines are given in table 1.1.

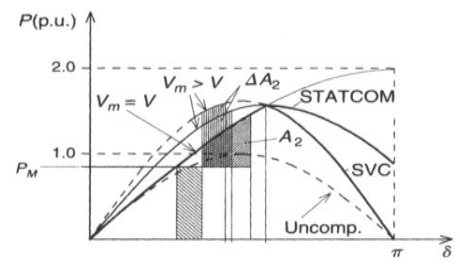

Figure-1 Enhancement of transient stability by SVC and STATCOM [2] 


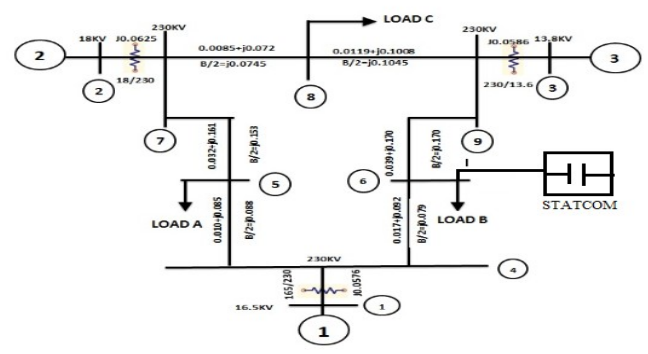

Figure-2 Nine Bus system with STATCOM [4]

III. Nine Bus System Generator Date

A. Table 1.1 Generator data for the three machines are given in table [4]

\begin{tabular}{|c|c|c|c|}
\hline Generator & 1 & 2 & 3 \\
\hline Rated MVA & 247.5 & 192.0 & 128.0 \\
\hline KV & 16.5 & 18.0 & 13.8 \\
\hline PF & 1.0 & 0.85 & 0.85 \\
\hline Type & Hydro & Steam & Steam \\
\hline Speed & $180 \mathrm{r} / \mathrm{min}$ & $3600 \mathrm{r} / \mathrm{min}$ & $3600 \mathrm{r} / \mathrm{min}$ \\
\hline Xd & 0.1460 & 0.8950 & 1.3125 \\
\hline X'd & 0.0608 & 0.1198 & 0.1813 \\
\hline Xq & 0.0969 & 0.8645 & 1.2570 \\
\hline X'q & 0.0969 & 0.1969 & 0.25 \\
\hline Xl(leakage) & 0.0336 & 0.0531 & 0.0742 \\
\hline$\tau$ 'do & 8.96 & 6.0 & 5.89 \\
\hline$\tau$ 'qo & 0.0 & 0.535 & 0.6 \\
\hline $\begin{array}{c}\text { Stored energy } \\
\text { At rated speed }\end{array}$ & $2364 \mathrm{MW} . \mathrm{s}$ & $640 \mathrm{MW} . \mathrm{s}$ & $301 \mathrm{MW} . \mathrm{s}$ \\
\hline
\end{tabular}

\section{B. V-I Characteristics of STATCOM}

The STATCOM is essentially an alternating voltage source behind a coupling reactance with the corresponding V-I and V-Q characteristics shown in figure-3(a) and 3(b). In these figure shows that the STATCOM can be operated over its full output current range at very low means theoretically zero, typically about 0.2 per unit system voltage levels. In other words say that, the maximum capacitive or inductive output current of the STATCOM can be maintained independently of the system voltage. The STATCOM is providing voltage support under large system disturbances during which the voltage excursions would be well outside of the linear operating range of the compensator. The figure 3(a) and 3(b) illustrate the STATCOM may, depending on the power semiconductors used, have an increased transient rating of both the inductive and capacitive operating regions

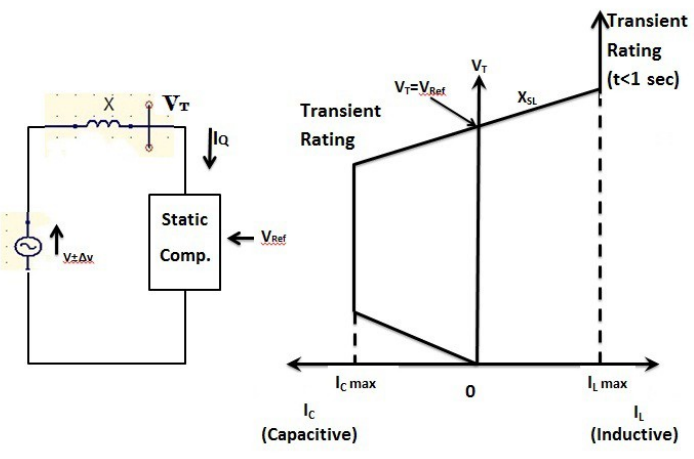

Figure-3 (a) V-I Characteristics of STATCOM [7] 


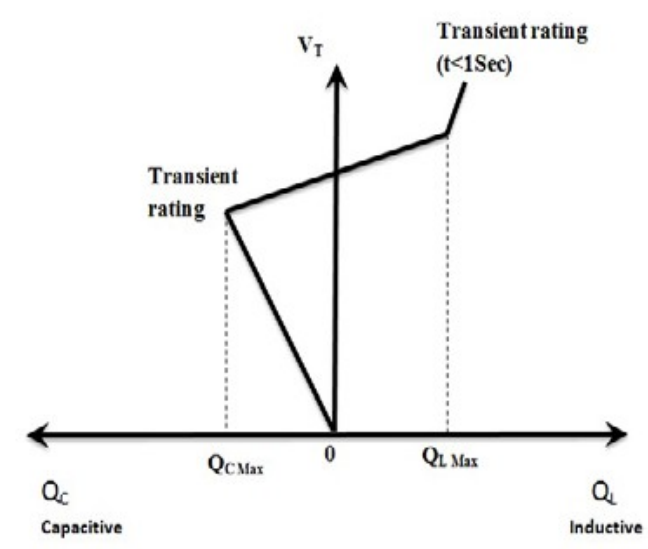

Figure-3 (b) V-Q Characteristics of STATCOM

\section{Modeling of STATCOM}

STATCOM (Static Compensator) has a characteristic similar to the synchronous condenser, but as an electronic device, it has no inertia and is superior to the synchronous condenser in several ways- better dynamics, a lower investment cost, and lower operating and maintenance costs. STATCOM is to be selected when the technical performance in a specific application so requires

[13] .However, utilizing thyristors with turn- off capability (GTO or IGBT), which is the common approach in the industry, does not allow the full potential of a STATCOM concept to be obtained. Figure-4 shows the modeling of STATCOM. STATCOM having six SCR which are connected parallel with diode for generating the pulse, also having a capacitor $300[\mu \mathrm{F}]$, it is used when the supply is disconnected.

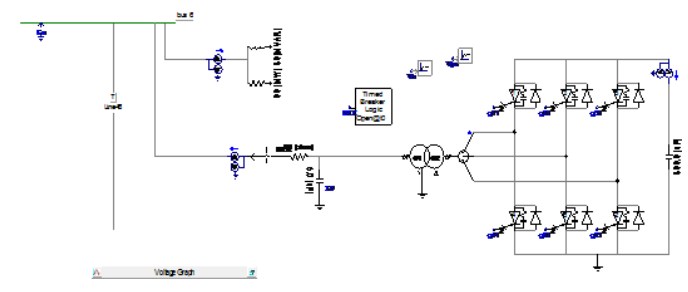

Figure -4 Modeling of STATCOM

\section{Simulation Modeling of STATCOM in}

\section{PSCAD}

Figure-5 shows the IEEE nine bus system with STATCOM, this is model of three phase fault with time logic in this model having when the fault occurs in the bus number- 5 . Here timed fault logic is connected for calculation of the sag and swell in transmission system during a period of a particular time. It is used for the

- Line to ground fault 


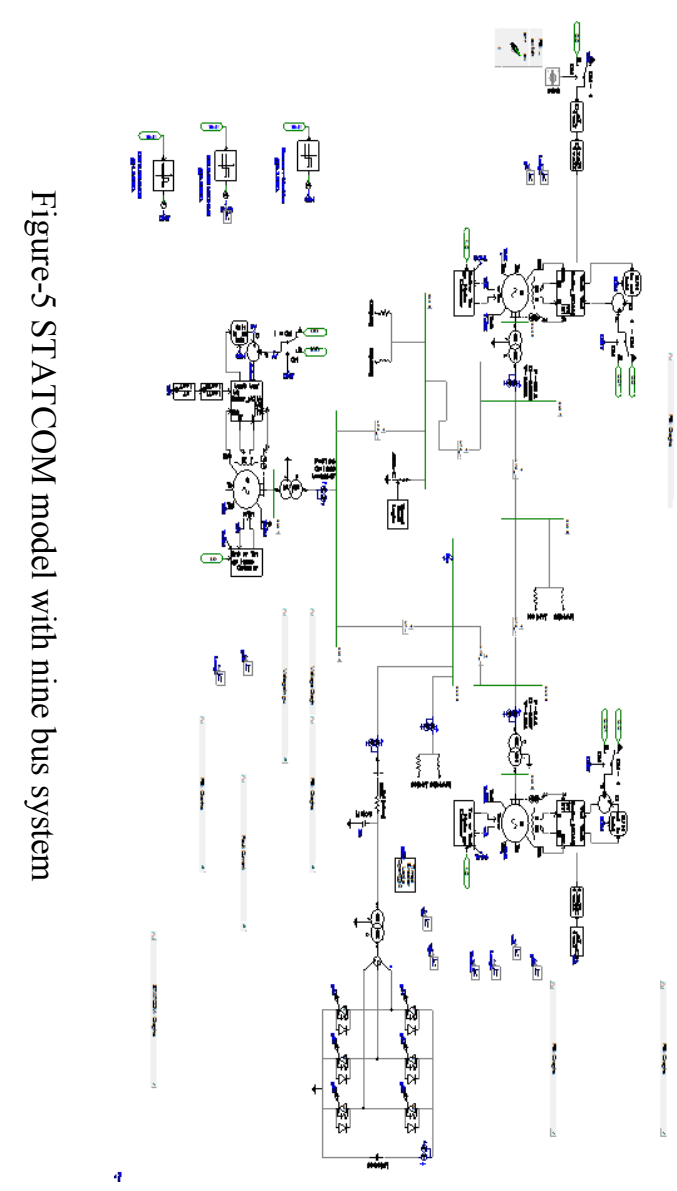

\section{Simulation and Results}

A IEEE nine bus system with and without STATCOM .In an six pulse STATCOM model, during working of the line, In this due to power swing, and load curve shows the transient stability and marginal stability in system, when the fault occur in system at bus 5 at time 1.0 second for duration of 0.75 second.

\section{(a) Stability Analysis in nine bus system with and without STATCOM}

\section{a) Power flow at Generator G1 and load angle}

Figure-6.1 shows the active power wave form at the generator G1, when the fault takes place at bus number-5 at time 1.0 second for duration of $0.75 \mathrm{~second}$. There is an instantaneous total or partial collapse of the bus voltage of the system. This is also results in the reduction of generator power output as shown in figure-6.1 wave form without STATCOM.

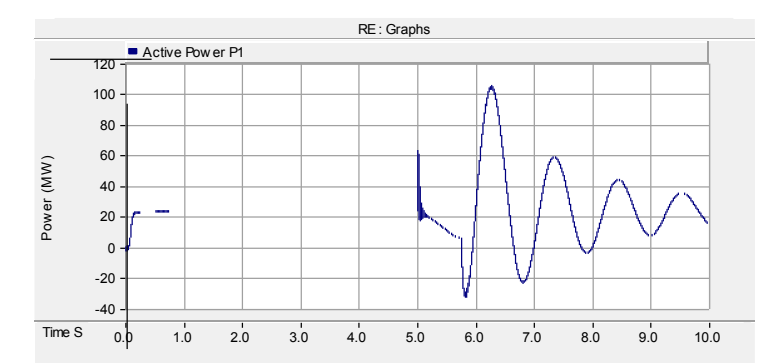

Figure- 6.1 Power flow wave form without STATCOM

Figure-6.2 shows the active power wave form at the generator G1 with STATCOM, when the fault takes place at bus number- 5 at time 1.0 second for duration of 0.75 second. It is quite necessary to simulate reduction of generator power output for more stable system so that used the nine bus system with STATCOM. 


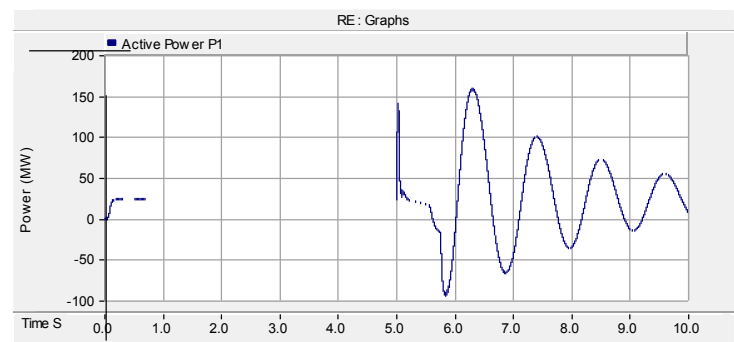

Figure- 6.2 Power flow wave form with STATCOM

Figure- 6.3 shows the load angle wave form at the generator G1, when the fault takes place at bus number-5 at time 1.0 second for duration of 0.75 second. There is an instantaneous total or partial collapse of the bus voltage of the system. This is also results in the reduction of generator by this load angle curve will goes to reduction of stability of nine bus system without STATCOM.

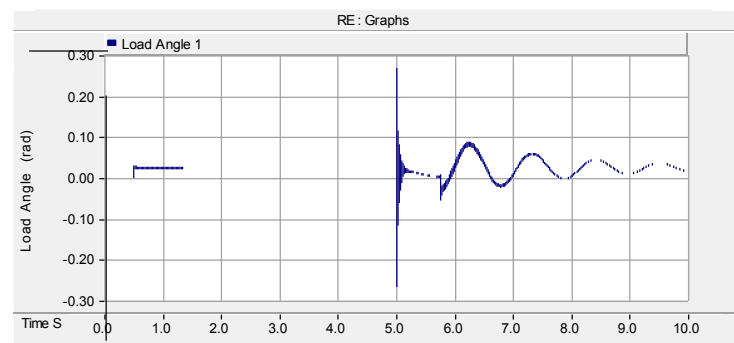

Figure- 6.3 Load angle wave form without STATCOM

Figure-6.4 shows the load angle wave form at the generator G1 with STATCOM, when the fault takes place at bus number-5 at time 1.0 second for duration of 0.75 second. It is quite necessary to simulate reduction of generator power output for more stable system so that used the nine bus system with STATCOM, by using STATCOM stability criteria will increases in load angle curve.

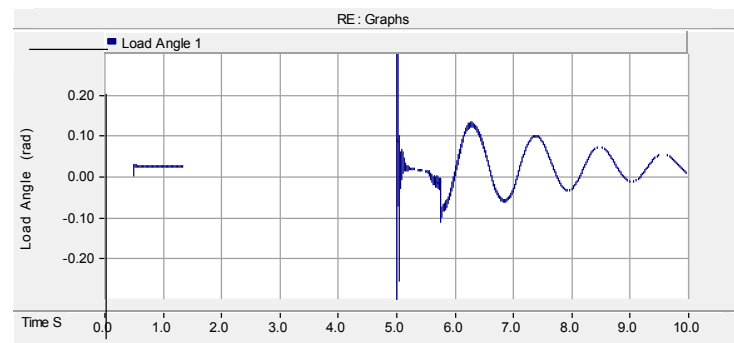

Figure- 6.4 Load angle wave form with STATCOM

\section{(b) Power flow at Generator G2 and load angle}

Figure-7.1 shows the active power wave form at the generator G2, when the fault takes place at bus number- 5 at time 1.0 second for duration of 0.75 second. There is an instantaneous total or partial collapse of the bus voltage of the system. This is also results in the reduction of generator power output as shown in figure-7.1 wave form without STATCOM.

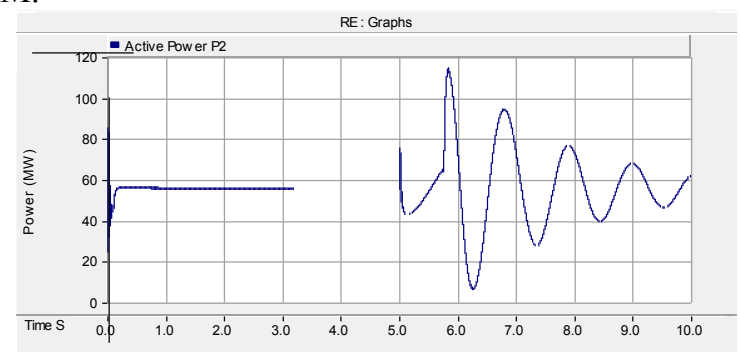

Figure- 7.1 Power flow wave form without STATCOM 
Figure-7.2 shows the active power wave form at the generator G2 with STATCOM, when the fault takes place at bus number-5 at time 1.0 second for duration of 0.75 second. It is quite necessary to simulate reduction of generator power output for more stable system so that used the nine bus system with STATCOM.

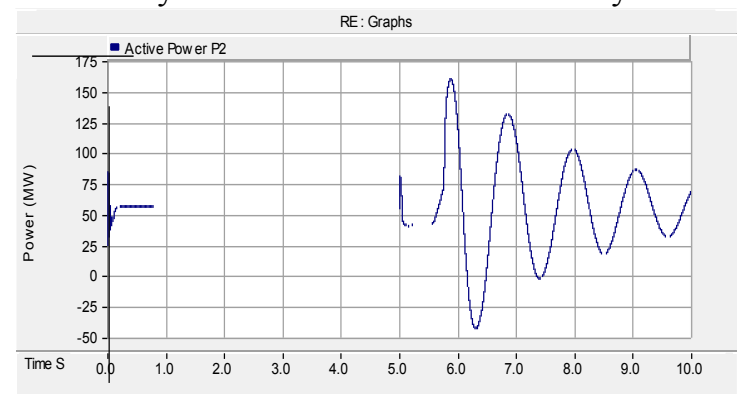

Figure- 7.2 Power flow wave form with STATCOM

Figure-7.3 shows the load angle wave form at the generator G1, when the fault takes place at bus number-5 at time 1.0 second for duration of 0.75 second. There is an instantaneous total or partial collapse of the bus voltage of the system. This is also results in the reduction of generator by this load angle curve will goes to reduction of stability of nine bus system without STATCOM.

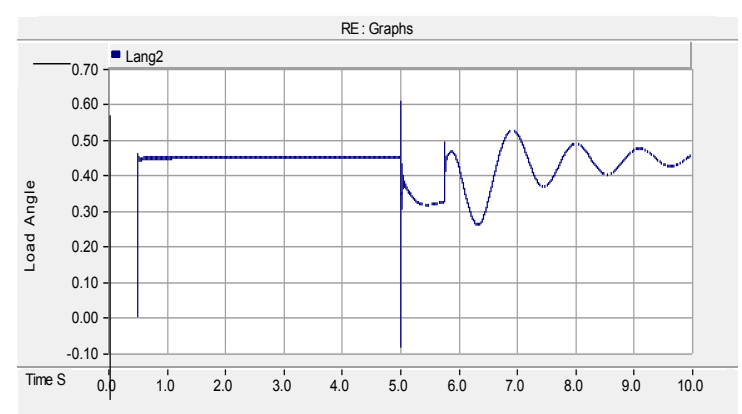

Figure- 7.3 Load angle wave form without STATCOM

Figure-7.4 shows the load angle wave form at the generator G2 with STATCOM, when the fault takes place at bus number-5 at time 1.0 second for duration of 0.75 second. It is quite necessary to simulate reduction of generator power output for more stable system so that used the nine bus system with STATCOM, by using STATCOM stability criteria will increases in load angle curve.

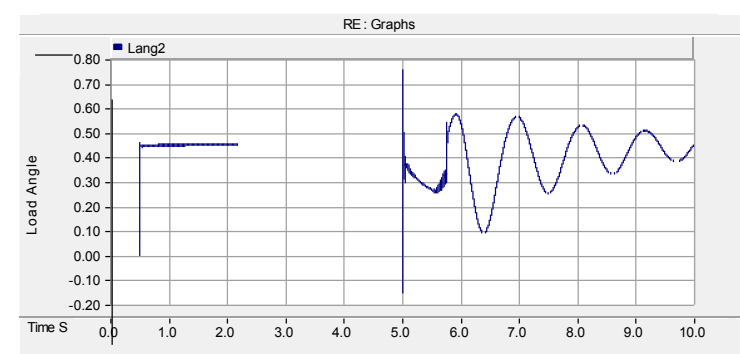

Figure- 7.4 Load angle wave form with STATCOM

(c) Power flow at Generator G3 and load angle

Figure-8.1 shows the active power wave form at the generator G3, when the fault takes place at bus number-5 at time 1.0 second for duration of 0.75 second. There is an instantaneous total or partial collapse of the bus voltage of the system. This is also results in the reduction of generator power output as shown in figure-8.1 wave form without STATCOM. 


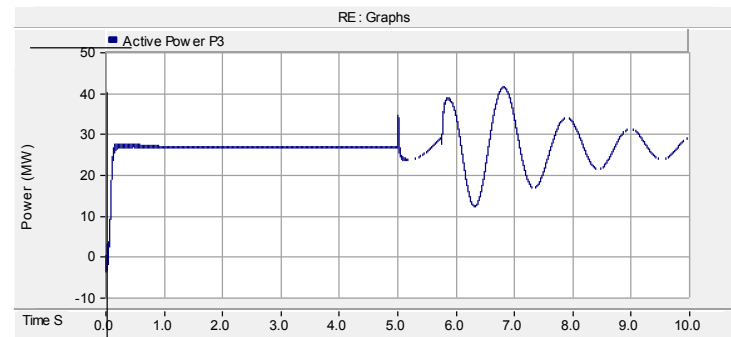

Figure- 8.1 Power flow wave form without STATCOM

Figure- 8.2 shows the active power wave form at the generator G3 with STATCOM, when the fault takes place at bus number- 5 at time 1.0 second for duration of 0.75 second. It is quite necessary to simulate reduction of generator power output for more stable system so that used the nine bus system with STATCOM.

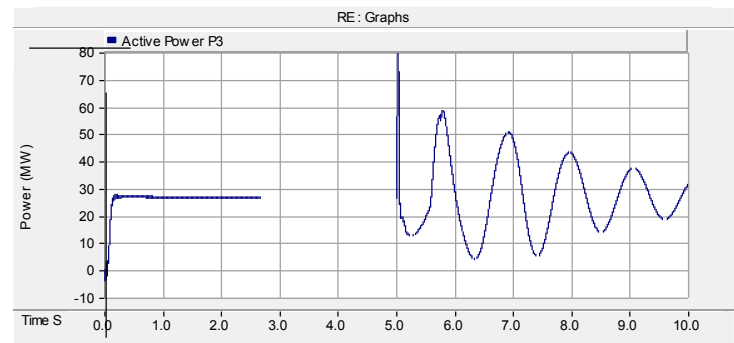

Figure- 8.2 Power flow wave form with STATCOM

Figure- 8.3 shows the load angle wave form at the generator G3, when the fault takes place at bus number- 5 at time 1.0 second for duration of 0.75 second. There is an instantaneous total or partial collapse of the bus voltage of the system. This is also results in the reduction of generator by this load angle curve will goes to reduction of stability of nine bus system without STATCOM.

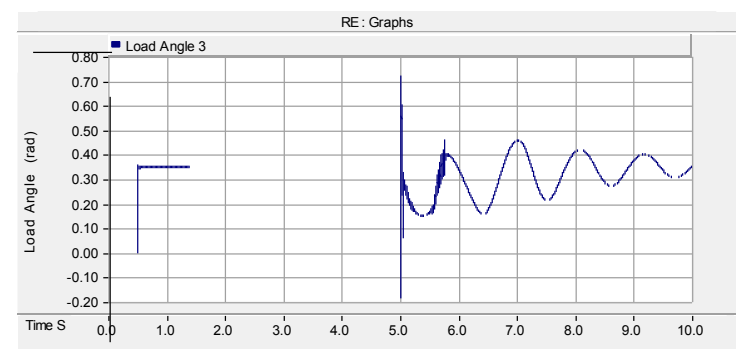

Figure- 8.3 Load angle wave form without STATCOM

Figure-8.4 shows the load angle wave form at the generator G3 with STATCOM, when the fault takes place at bus number-5 at time 1.0 second for duration of 0.75 second. It is quite necessary to simulate reduction of generator power output for more stable system so that used the nine bus system with STATCOM, by using STATCOM stability criteria will increases in load angle curve.

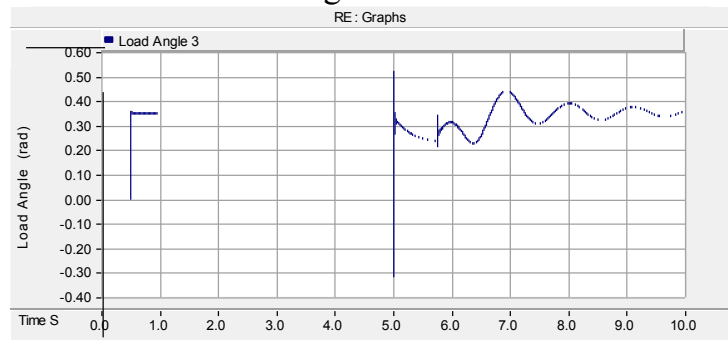

Figure- 8.4 Load angle wave form with STATCOM

\section{Conclusions}

In this paper the capability of STATCOM, for enhancement of stability is presented. When the disturbance takes place at bus number-5, the power swing and load angle variation compared with and without STATCOM. The results are agree for the device as expected. At that time stability graph decreases, with decreasing in active power and load angle. At that time when system will work with STATCOM stability curve 
increases with increasing active power and load angle, by this action system will become more stable than earlier(without STATCOM).

\section{References}

[1] Beaulieu G., Bollen, M.H.J, Malgarotti S. and Ball R., Power quality indices and objectives. Ongoing activities in CIGRE WG3607.Power Engineering Society Summer Meeting, 2002. IEEE, Volume:2, 21-25 July 2002, Pages: 789 - 794 vol.-2.

[2] M.H.J. Bollen, Understanding Power Quality Problems: Voltage Sags and Interruptions. New York, IEEE Press, 1999.

[3] M.H.J. Bollen, L.D.Zhang, Different methods for classification of three-phase unbalanced voltage dips due to faults. Electric Power Systems Research, Volume 66, Issue 1 2003, pages 59-69.

[4] P.M. Anderson and A.A. Fouad, "Power System Control and Stability", the IOWA state university press AMES IOWA USA, volume I, first edition 1977, chapter 2, page 37-38.

[5] Mehrdad Ahmad, Mostafa Alinezhad, "Comparison of SVC and STATCOM in Static Voltage Stability Margin Enhancement", Proceedings of World Academy of Science, Engineering and Technology, Vol. 38, Feb. 2009.

[6] Y.H. Song and A.T. Johns, "Flexible ac transmission systems (FACTS)", The Institute of Electrical Engineers, London, 1999.

[7] N.G. Hingorani and L. Gyugyi, "Understanding FACTS: concepts and technology of flexible ac transmission systems", IEEE Press,NY, 1999.

[8] K. R. Padiyar and A. L. Devi, "Control and simulation of static condenser," in Proc. 9th Annu. Applied Power Electronics Conf. Expo., Feb. 13-17, 1994.

[9] P. Rao, M.L. Crow and Z. Yang, "STATCOM Control for Power System Voltage Control Applications", IEEE Transactions on Power Delivery, Vol. 16, pp. 18-23, 2000.

[10] M.F. McGranaghan, D.R.Mueller, M.J.Samotyj, Voltage sags in industrial systems, IEEE Trans. Industry Applications, Vol.29, no.2, March/April 1993, pp.397 - 403.

[11] Ambra Sannino, Power Quality and Electromagnetic Compatibility Courses Compendium, Chalmers University of Technology, Dept. of Electric Power Engineering, Spring 2004.

[12] V. Kaura and V. Blasko, Operation of a Voltage Source Converter at Increased Utility Voltage, IEEE Transactions on Power Electronics, Vol.12, No. 1, Jan 1997, pp. 132 - 137.

[13] Christian Dufour, Simon Abourida, Jean Belanger,Vincent Lapointe," InfiniBand-Based Real-Time Simulation of HVDC, STATCOM, and SVC Devices with Commercial-Off-The Shelf PCs and FPGAs”, Opal-RT Technologies Canada.

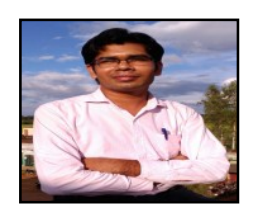

Pushp Rai Mishra, he received his DIPLOMA in Electrical Engineering from B.R.P. Govt. Polytechnic Rudri Dhamtari (C.G.). He obtained his B.E. degree in Electrical Engineering from SSCET Junwani Bhilai (C.G.), pursuing his M. Tech, in Power System Engineering from Dr. C.V. Raman University Kargi Road Kota Bilaspur (C.G.)

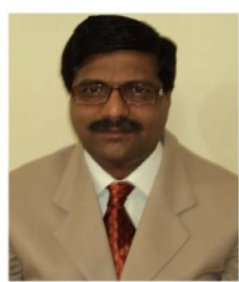

S.B. Warathe was born in Multai, India, in 1966. He received his B.E. degree in Electrical Engineering from Govt. Engineering College, Jabalpur. He obtained his M.E. degree in Electrical Engineering from CSVTU Bhilai (C.G.) India. Mr. Warathe is presently working as Selection grade Lecturer in Electrical Engineering (Gazetted class-I) in Govt. Polytechnic Durg. His areas of interest are poly phase order transmission, load flow, power quality, FACT device, wind farm, stability, protection numerical relay, IEC6180, computer aided analysis of power systems. 